\title{
A CRITICAL DISCOURSE ANALYSIS ON THE FRAMING OF THE FEMINIZATION OF FORCED DISPLACEMENT
}

by

Samantha DeBoer, BA, Wilfrid Laurier University, 2014

\section{A Major Research Paper \\ Presented to Ryerson University}

In partial fulfillment of the requirements for the degree of

\author{
Master of Arts \\ in the Program of \\ Immigration and Settlement Studies
}

Toronto, Ontario, Canada, 2016

(C) Samantha DeBoer, 2016 


\section{AUTHOR'S DECLARATION}

I hereby declare that I am the sole author of this Major Research Paper. This is a true copy of the MRP, including any required final revisions, as accepted by my examiners.

I authorize Ryerson University to lend this MRP to other institutions or individuals for the purpose of scholarly research.

I further authorize Ryerson University to reproduce this MRP by photocopying or by other means, in total or in part, at the request of other institutions or individuals for the purpose of scholarly research.

I understand that my MRP may be made electronically available to the public.

Samantha DeBoer 


\title{
A CRITICAL DISCOURSE ANALYSIS ON THE FRAMING OF THE FEMINIZATION OF FORCED DISPLACEMENT
}

\author{
Samantha DeBoer
}

Master of Arts 2016

Immigration and Settlement Studies

Ryerson University

\begin{abstract}
The Major Research Paper seeks to examine the discursive practices that frame the issue of the feminization of forced displacement and construct representations of forcibly displaced women. It will examine the discourse that constructs representations of forcibly displaced women, which has implications for their protection and treatment in society. Forcibly displaced women are victimized through the representational discourse in terms of how they are spoken about and their visual depictions (Johnson, 2011). Based on feminist theory, the conceptual framework of the gender binary, gender and cultural essentialism, representations of victims, the discourse of victimization, and global feminism will be applied to a critical discourse analysis of the UHCR Handbook for the Protection of Women and Girls. This paper argues that the linguistic constructs and discursive practice contribute to misrepresentations of forcibly displaced women.
\end{abstract}

Key Words: Feminization, Forced Displacement, Women, Refugees, UNHCR, Discourse 


\section{ACKNOWLEDGEMENTS}

I would like to thank my supervisor, Dr. Amina Jamal, for her support and guidance throughout the MRP writing process. She played a major role in shaping this paper through her thoughtful insight and constant guidance. I would also like to thank my second reader, Dr. Camille Hernandez-Ramdwar for taking the time to read my paper and provide feedback.

In addition, I would like to acknowledge the faculty and students in the Immigration and Settlement Studies program for the knowledge shared amongst each other and the immense learning experiences. Lastly, I would like to thank my family for their ongoing encouragement and support throughout this year and especially the writing process. 


\section{TABLE OF CONTENTS}

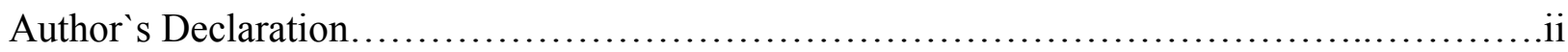

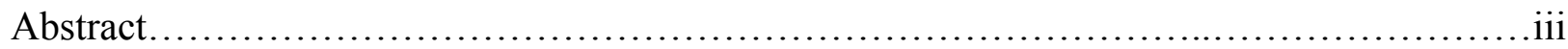

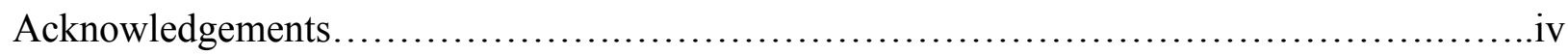

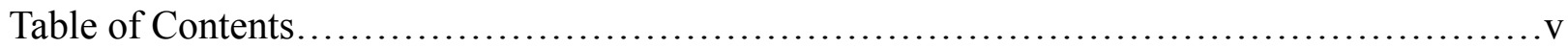

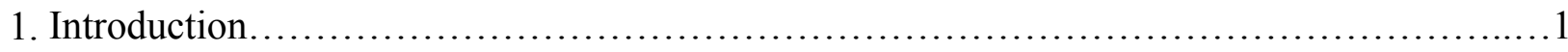

1.1 Research Focus..................................................................

1.2 Organizational Structure ..........................................................

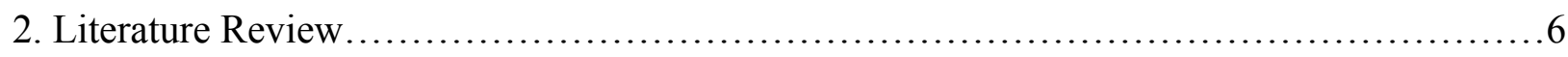

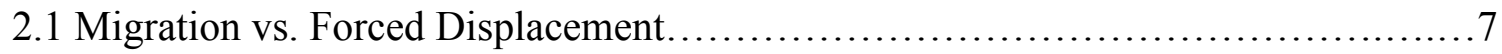

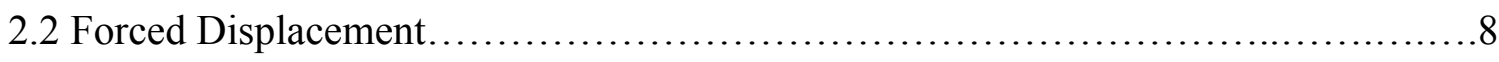

2.3 Contributing Factors to the Feminization of Forced Displacement....................9

2.4 The term 'feminization' ...................................................... 11

2.5 Feminization of Forced Displacement: Current Situation and Statistics.............13

2.6 Feminization of Forced Displacement: as Described in the Literature................14

2.7 Literature Appraisal....................................................... 15

2.8 Situating Research......................................................... 16

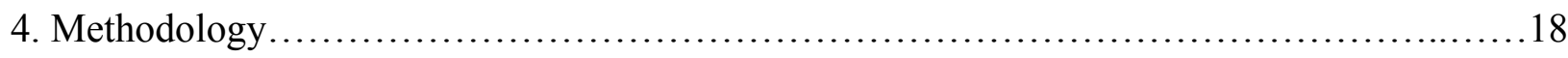

4.1 Research Problem........................................................ 18

4.2 Research Questions..................................................... 18

4.3 Conceptual Framework......................................................... 18

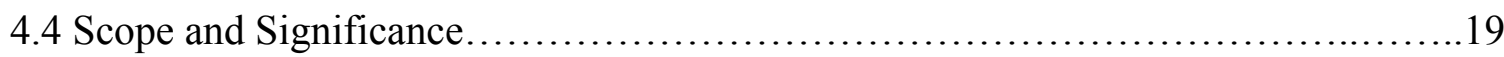

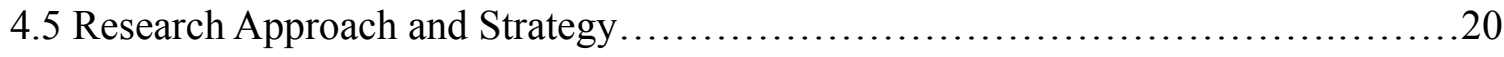

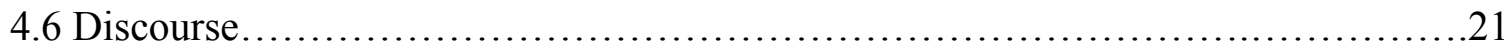

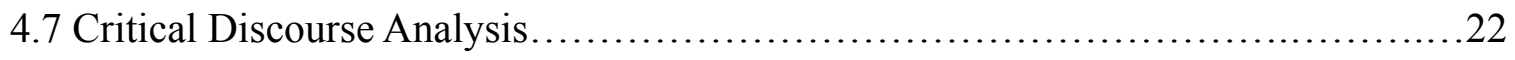

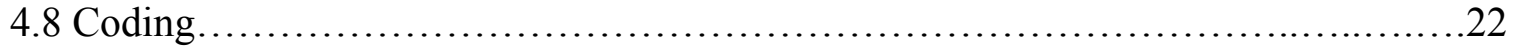

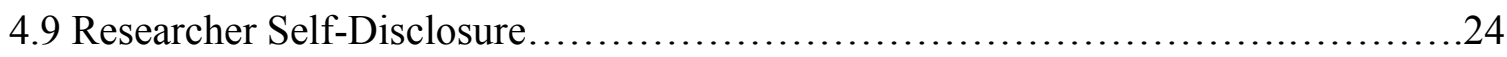

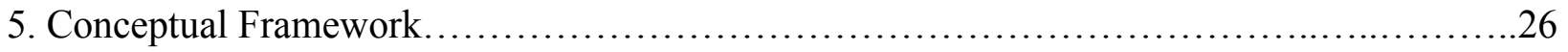




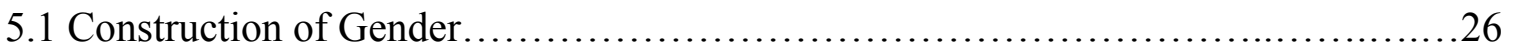

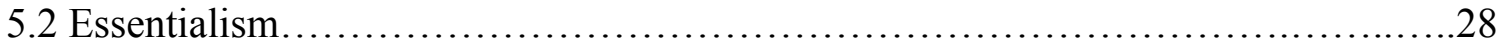

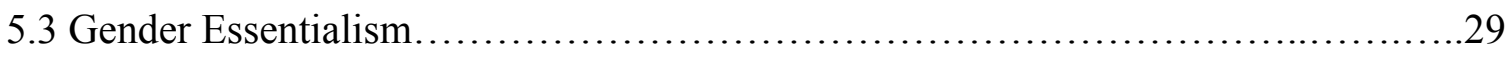

5.4 Cultural Essentialism...................................................... 30

5.5 Representations: Victims.................................................... 31

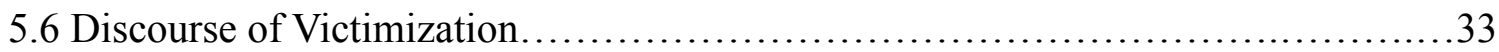

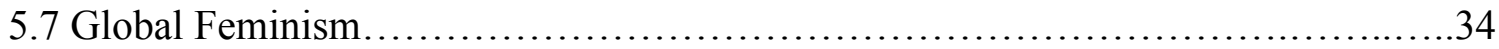

6. Critical Discourse Analysis of the UNHCR Handbook......................................36

6.1 Binary of Gender Relations.....................................................

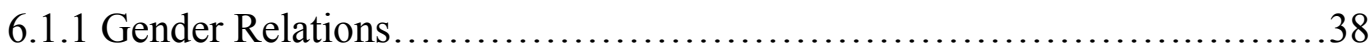

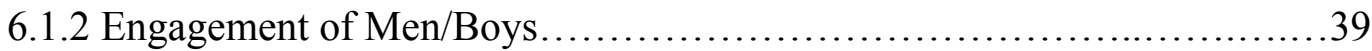

6.1.3 Gendered Power Relations...........................................40

6.2 Terms Contributing to the Discourse of Victimization.............................41

6.2.1 'Empower', 'Victim' and 'Survivor....................................41

6.2.2 'Challenge' and 'Obstacle' ..............................................45

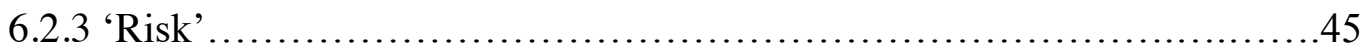

6.3 Construction of Absolute Terms and Relative Terms.............................47

6.3.1 'Often', 'Generally' and 'Usually'......................................47

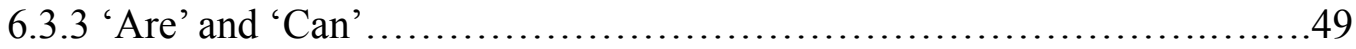

6.3 .4 'No One' and 'Some' ...............................................50

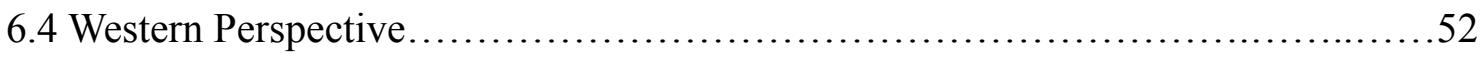

6.4.1 UNHCR Position..................................................5

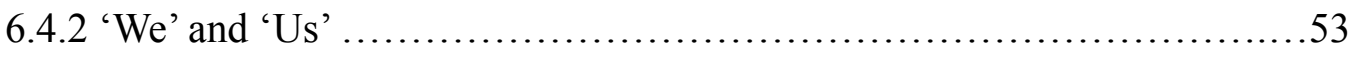

6.5 Conclusion of the Critical Discourse Analysis....................................55

7. Discursive Implementation of Policy: A Case Study of Canada's Role.......................56

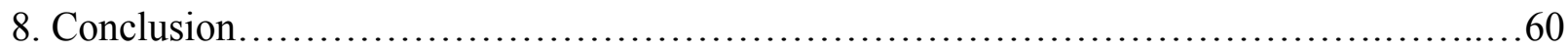

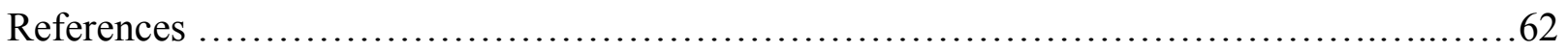




\section{Introduction}

As the largest governing body in the refugee regime, the United Nations High Commissioner of Refugees (UNHCR) has the most influence on state policies pertaining to the protection of forcibly displaced persons and more specifically forcibly displaced women. The main actors in the refugee regime are the UNHCR, NGOs, the host governments, and the refugees themselves (Edward, 2007). Zetter (1999) states that NGOs from the Global North dominate the agenda of the refugee regime to reinforce their own power and control. Policies within the refugee regime have been predominantly shaped by men, most notably starting from women being left out of drafting the 1951 United Nations Convention (Gerard, 2014). The lack of involvement of women resulted in the male refugee experience being "presented as the norm for international refugee legal protection, and women and their experiences [being] judged as secondary in importance" (Edwards, 2010, as cited in Gerard, 2014, p. 60). Thus, it is necessary to critique UNHCR documents through a gender perspective or feminist lens in order to address the needs of forcibly displaced women, due to the large population of women affected and their particular protection needs.

Forced displacement is often the result of the denial of rights (Buscher, 2009). Forced displacement refers to the "situation of persons who are forced to leave or flee their homes due to conflict, violence, and human rights violations" (World Bank, 2015). The feminization of forced displacement as "the phenomenon in which women represent an increasingly disproportionate percentage of displaced population worldwide" (Gusman, 2013, p.429). In terms of legal protection, conflict and displacement exacerbate the structural inequality that underwrites the systemic violations of women's rights (Macklin, 2009). Legal factors contribute to the 
feminization of forced displacement based on the lack of protection for women both in their country of origin and throughout the migration process. As a result of the feminization of forced displacement being a trend with disproportionate consequences for women, many policies have been 'gender-blind' (Gusman, 2013). As forced displacement affects men and women differently, there requires protection strategies which recognize these differences (Gusman, 2013). Gender analysis is important for legal protection because of the pre-existing power relations that put women at a disadvantage and further marginalize women in situations of forced displacement. During the 1985 gender and development debate of feminist literature, there was a challenge of the negative perception of refugee women (Moussa, 1998). There was a shift in focus from the concept of women in development (WID) to gender and development (GAD), with the main change that women went from being integrated into "existing unequal societal structures" to women being viewed as "agents and beneficiaries of development" (Antrobus, 1991; Sen and Grown, 1987, as cited in Moussa, 1998). This shift continues to have a major impact on how policies and documents at the international level are now written; with a better somewhat recognition of their agency and autonomy. Starting in the 1990s, international policies and documents pertaining to the protection of forcibly displaced women began being implemented (Moussa, 1998). Policies and protection developments for refugee women began emerging since the UNHCR released the Policy on Refugee Women in 1990 (Buscher, 2010). Since this first policy was created, other notable documents have materialized including: Guidelines on the Protection of Refugee Women (1991), the High Commissioner's Five Commitments to Refugee Women (2001), the Sexual and Gender-Based Violence Guidelines (2003), the Age, Gender and Diversity Initiative (2004-2006). The most recent development is 
the 2008 Handbook for the Protection of Women and Girls, which replaced the 1991 Guidelines on the Protection of Refugee Women (UNHCR, 2008). These documents and policies focusing on the protection of forcibly displaced women since the early 1990s have made numerous advancements at the international level (Buscher, 2010), though their discursive practices must still be critiqued in order to address the representation and framing of forcibly displaced women.

\subsection{Research Focus}

The Major Research Paper seeks to examine the discursive practices that frame the issue of the feminization of forced displacement and construct representations of forcibly displaced women. It will examine the discourse that constructs representations of forcibly displaced women, which has implications for their protection and treatment in society. Forcibly displaced women are victimized through the representational discourse in terms of how they are spoken about and their visual depictions (Johnson, 2011). There have been gender assumptions perpetuated in refugee policy about women's “inherent vulnerabilities and innocence” (Johnson, 2011). There are current portrayals of refugees as nameless and voiceless victims without any agency (Johnson, 2011). This portrayal of forcibly displaced is as a nameless figure that represents a large and diverse population, rather than an individual woman or groups that are resilient or empowered. Hyndman and Giles (2011) state that researchers and writers contribute to producing and reproducing voiceless and passive refugees by representing them as being helplessly in need of solutions to their problems. As a result, the discourse of these representations must be analyzed in order to examine the ways in which writing and language contribute to this issue. 
The document that will be used for critical discourse analysis is the UNHCR Handbook for the Protection of Women and Girls, which is a tool that takes multiple approaches to achieving the empowerment of displaced women and girls through the promotion of gender equality (UNHCR, 2008). The introduction of the Handbook states that the document "describes some of the protection challenges faced by women and girls of concern to the Office of the United Nations High Commissioner for Refugees and outlines various strategies [that the UNHCR] should adopt with [their] partners to tackle these challenges" (UNHCR, 2008, p. 1). The women and girls that are of concern to the UNHCR are "asylum seekers, refugees, internally displaced, returnees, stateless, or those who have integrated into new communities" (UNHCR, 2008, p. 1). The Handbook also states that it has legal standards and principles to guide the work of states and other actors (UNHCR, 2008). Its intended audience is for UNHCR staff, in order to fulfill their responsibilities of effectively protecting women and girls (UNHCR, 2008). This background information has been provided in order to explain the context of the Handbook in terms of its purpose and group of concern.

\subsection{Organizational Structure}

The structure of this paper is organized as follows. A literature review will provide the context of the issue of the feminization of forced displacement in terms of existing research and conceptualization of the issue. The methodology section will provide an in-depth explanation of the research problem and questions, reasoning for the conceptual framework, the scope and significance, the research approach and strategy, the concept of discourse and the process of critical discourse analysis, the tool of coding, and lastly, it will provide a researcher selfdisclosure. The conceptual framework section will explain the construction of the gender binary, 
essentialism, gender essentialism, cultural essentialism, representations of victims, the discourse of victimization, and global feminism. The components of the conceptual framework will then be applied in the critical discourse analysis of the Handbook, which is the main body of this paper. The critical discourse analysis section has four areas of examination: the binary of gender relations, terms contributing to the discourse of victimization, the construction of absolute terms and relative terms, and the Western perspective. The last section of this paper will bring the focus from international to national, as it looks at Canada's role in the discursive implementation of policy. This organizational structure is based on the progression of sections that build upon one another and inform the critical discourse analysis, for the ultimate purpose of addressing the research questions. 


\section{Literature Review}

The feminization of forced displacement describes the increasing international prevalence of women becoming refugees or internally displaced. The rising trend of forcibly displaced women being disproportionately represented on the global scale is significant for study because there is a shortage of substantive literature or research on this particular issue. The existing body of literature lacks scholarly research on the conditions that create gendered forced displacement, though this is vital because the intersection of gender and forced displacement complicates situations of protection for women. In order to understand issues of protection for forcibly displaced women, it is important to first research and examine the contributing factors to the feminization of forced displacement. For the purpose of addressing these gaps in research, this literature review will provide a comprehensive review of the following topics: the difference between migration and forced displacement, a more in-depth examination of forced displacement, the contributing factors to the feminization of forced displacement, the term 'feminization', the current situation of forcibly displaced women, how the feminization of forced displacement is discussed in scholarly literature, and lastly an appraisal of the existing body of literature on this issue. This literature review is also conducted for the purpose of providing a framework for the terminology and concepts that are significant to discussion of the feminization of forced displacement. The literature review concludes by situating the research of this paper in the existing literature and research on the feminization of forced displacement. By conducting this literature review on the areas described, I will demonstrate how my own research addresses these research gaps. 


\subsection{Migration vs. Forced Displacement}

The feminization of migration is a prominent issue within scholarly research, in addition to being discussed more frequently and in depth in comparison to the feminization of forced displacement. There are significant differences between the circumstances of the feminization of migration and the feminization of forced displacement. These differences are necessary to distinguish in the interest of demonstrating the significance of research on the feminization of forced displacement. The characteristics of the feminization of forced displacement are comparable to those of the feminization of migration, but with an intensification and negative implications due to the circumstances of being a refugee or internally displaced. Literature about the feminization of migration focuses on the process by which women are increasingly becoming migrants as independent workers and often separate from their families (Verschuur, 2013). Migration is feminized both among the low skilled labour force and high skilled workers with the ability to migrate (Ghosh, 2016). Global economic restructuring relates to the changes in the division of labour and subsequently the feminization of migration (Verschuur, 2013). It is inferred that one of the reasons for the feminization of migration being researched at length is due to it being a positive trend as a result of the neoliberal interest of economic distribution, whereas the feminization of forced displacement is a negative trend as a result of gendered risk and lack of protection. The feminization of forced displacement is problematized in research, as the context of the global refugee crisis has increasingly negative consequences for the growing number of displaced persons. Thus, the feminization of forced displacement is an issue that must be researched further in order to better understand and better assist the millions of women affected by its negative implications. 


\subsection{Forced Displacement}

Before analyzing the issue of the feminization of forced displacement, this section will provide context for both the issue of forced displacement and the role of the UNHCR. Forced displacement refers to the "situation of persons who are forced to leave or flee their homes due to conflict, violence, and human rights violations" (World Bank, 2015). Among those that are forcibly displaced, there are distinctions between refugees and internally displaced persons. A refugee is an individual that is forced to flee their country because they have a "well-founded fear of persecution for reasons of race, religion, nationality, political opinion, or membership in a particular social group" (Betts, Loescher, \& Milner, 2008). An internally displaced person is an individual that is forced to leave their home for similar reasons as a refugee but have not crossed international borders outside of their country and are not protected by international law (Betts et al., 2008). The main instrument of refugee law is the 1951 Refugee Convention, which designates those who qualify as refugees and determines the type of legal protection they should receive (Betts et al., 2008).

The UNHCR is the international organization that addresses issues of forced displacement through various avenues including the creation of policies and humanitarian activities in the field. The work of the UNHCR has evolved over time, from its geographic expansion outside of Europe in the 1950s, its greater material assistance role in the 1980s, and its increased involvement in humanitarian protection in the 1990s (Betts et al., 2008). Forced displacement is in its most rapid period of change since the UNHCR was first created in 1950, which has raised issues as to how the UNHCR should fulfill its protection mandate (Betts et al., 2008). In the 21 st century, the UNHCR has new challenges that shape new questions about who 
to protect and how to protect (Betts et a., 2008). In the case of this paper, the UNHCR has challenges in protecting forcibly displaced women as a result of the victim-centred representation of their situations being improperly problematized in terms of gendered risk and protection needs. The progression of the UNHCR is important to examine because of its powerful influence in areas of protection for forcibly displaced women and its way of addressing the feminization of forced displacement.

\subsection{Contributing Factors to the Feminization of Forced Displacement}

The causes and consequences of forced displacement are connected to wider trends internationally (Betts et al., 2008). There are political, social, and environmental factors that exacerbate the conditions of forcibly displaced women. These factors are closely linked and intersect in many contexts to increase the prevalence of the feminization of forced displacement. This section will provide an overview of the contributing factors to the feminization of forced displacement and their implications for gendered risks and protection needs.

Political clashes and instability cause conflict and violence. Displacement can occur as a result of people fleeing to avoid anticipated conflict, ongoing conflict, and consequences of past conflict (Macklin, 2009). During war and conflict men, women, and children are all vulnerable to human rights abuses but women and girls are especially vulnerable to sexual violence (Moussa, 1998). Conflicts are never gender-neutral, as women disproportionately face the costs of economic deprivation, poverty, or gender-based violence (Gusman, 2013). Sexual violence is used as a strategy of war to "destabilize, threaten, and dominate a community of refugees of an enemy, and to force communities off their land" (Giles, 2013, p.89). Women can experience sexual violence as a form of intimidation to reveal political information or as punishment for not 
conforming to certain cultural norms (Moussa, 1998). Sexual and gender-based violence can be both a cause of forced displacement and also part of forced displacement experiences (Gusman, 2013). Armed conflict is one of the main causes of forced displacement and it can intensify gender discrimination already within society that women face before displacement (Gusman, 2013). The impacts of political conflicts intersect with the gendered social conditions and further complicate situations for women.

The experiences of forcibly displaced women may include the social reconstruction of gender identities and gender relations, due to previous gender and family roles coming under strain in forced displacement contexts (Veney, 2007). Gender roles make women vulnerable to being coerced into the demands of men that control resources, in order to provide for their families (Rider, 2012). Forced displacement weakens the existing protection mechanisms of community and family, which exposes women to human rights violations, abuse, and exploitation (Gusman, 2013). During forced displacement, women can experience social disadvantages including gender inequalities, trauma, fear of sexual violence, reduced community resources, and family needs (Wood, 2006, as cited in Rider, 2012). Prior to war and disasters, the gendered experiences of women affects their situations during and afterward, including their ability to flee as a result of responsibility for dependents, access to resources, and mobility (Giles, 2013).

Environmental factors contributing to forced displacement are broadly attributed to climate change and degradation of safe environmental conditions. More specifically, the environmental factors including the loss of livelihoods, illness, and hunger are all contributing factors to situations of forced displacement (Martin and Tirman, 2009). During a conflict, 
livelihoods are disrupted and the regular activities of farming or other business are unable to continue, which precipitates forced displacement through the loss of capacity for self-support (Martin and Tirman, 2009). Gendered inequalities and social exclusion mean that women may not have control over resources and these conditions may force them to migrate for food, resources, and security (Buscher, 2009). This forces women to experience the dire consequences of environmental issues (Buscher, 2009).

These contributing factors are necessary to address when discussing the experiences of forcibly displaced women in order to gain an understanding that there is a range of factors leading to these situations. The many reasons and intersections of events that contribute to forced displacement are unique to every situation.

\subsection{The term 'feminization'}

As a general definition, the term 'feminization' describes the process by which a condition, trend, or phenomenon has a disproportionately high involvement of women. According to Hyndman and Giles (2011), feminization can "lead to the attribution of certain programmes, practices and identities as passive, helpless, static, but it can also signal the gendering of labour market segmentation and the production of inequalities" (p. 263). It is a term that can be applied to the various phenomena that affect women disproportionately. For example, the 'feminization of poverty' describes how women are at a higher risk than men of living in poverty in industrialized countries, which comes as a result of their positions in society as women (Hyndman and Giles 2011). Echoing this point, Gusman (2013) states that the conditions of the 'feminization' of issues display that women experience a disproportionate burden for 
social equality. Now that the term 'feminization' has been explained, the concept of the 'feminization of forced displacement' will be examined.

Within the literature on forced displacement, there are discrepancies in regards to what the term 'feminization' describes, and how it should be measured (Vause and Toma 2015). Vause and Toma (2015) state that most researchers and policy reports define feminization as "an increase in the share of women in the migration stream" (p. 41). Gusman (2013) describes the feminization of forced displacement as "the phenomenon in which women represent an increasingly disproportionate percentage of displaced population worldwide" (p.429). Hyndman and Giles (2011) characterize the feminization of a phenomenon as "a shift in gender relations towards those considered female or feminine" (p.363) or signalling the production of inequalities. The various authors cited in this section define the feminization of forced displacement in similar ways. These definitions are the framework for understanding the issue of the feminization of forced displacement in this paper.

There is another definition of the term 'feminization' in forced displacement literature. Hyndman and Giles (2011) argue that feminization does not only refer to women but can also describe the emasculation of men ${ }^{1}$. This concept will not be used in this paper because it addresses a process that does not directly relate to the issue of the disproportionate prevalence of women as refugees and internally displaced persons. The definition of 'feminization' that will be used in this paper describes the broader process of forced displacement.

\footnotetext{
${ }^{1}$ Hyndman and Giles (2011) have a unique stance on the feminization of spaces in which refugees exist in. The feminization of asylum describes "the material conditions and depictions of such refugees as immobile and passive", which addresses the power relations that refugees experience when they are in long-term limbo (Hyndman and Giles, 2011, p.361).
} 


\subsection{Feminization of Forced Displacement: Current Situation and Statistics}

In order to provide context for the issue, the current situation and statistics are examined in this section. The current global refugee situation is not temporary, but rather it is a continuous phenomenon (Moussa, 1998). As of 2016, it is estimated that there are over 65.3 million forcibly displaced persons worldwide (UNHCR, 2016). This recent figure exemplifies the magnitude of the global crisis of forced displacement, but there are differing statistics about the percentage of women that are included in this large figure. The literature on gender and refugee protection does not take into account the growing number of forcibly displaced women and data collection on the topic is unsystematic and incomplete (Bhabha, 2004, as cited in Gerard, 2014). According to Martin (2004), an estimated 70-75\% of all refugees and displaced persons worldwide are women and their dependent children (as cited in Martin and Tirman, 2009). Giles (2013) states another figure, that approximately $80 \%$ of internally displaced persons worldwide are women and children. In terms of geographic distribution, Macklin (2009) contends that the majority of the forcibly displaced persons in the world do not cross state borders, therefore being internally displaced and that the majority is also female. There is a lack of disaggregated data on the numbers of forcibly displaced women separate from children, as these groups are often conflated in statistics (Gerard, 2014). The unreliability of statistics pertaining to forcibly displaced women is problematic in that it fails to provide a complete picture of the issue of gender and refugee protection (Gerard, 2014). Nonetheless, these statistics and figures provide context for the magnitude of the issue of forced displacement and in particular the feminization of forced displacement. Furthermore, these statistics prescribe the need for research on this global issue. 


\subsection{Feminization of Forced Displacement: as Described in the Literature}

There is a consensus among scholars that women are overrepresented amongst refugee populations, with consistent arguments made that the feminization of forced displacement should be more heavily researched in recent decades. Vause and Toma (2015) state that the feminization of forced displacement is not a new phenomenon, but that it was absent in literature until the 1980s and even though it has been discussed more, the data on these migration flows are largely still unavailable. The refugee regime movement has caused an increased volume of research and scholarly literature on forced migration and refugee issues (Edward, 2007). Macklin (2009) makes a similar point, as she states that in the mid-1980s gender emerged on the international refugee agenda and has continued to gain attention on international and national levels. Giles (2013) states that feminist research on the unequal gender relations and experiences of refugee women became available by the late 1980s. Piper (2006) also states that studies on migration flows have focused on the condition of feminization as an important contemporary feature since the 1980 s.

Castles and Miller (2009) argue that women are playing an increasing part in all types of migration and in all regions, though the majority of literature is focused on the economic migration of women. One of the challenges in the existing research is that it mainly focuses on the gendered migration patterns of a single country, but there is a need for a comparative approach to understanding the gender relations of international mobility (Vause and Toma, 2015). Overall, these sources argue that the feminization of forced displacement has been increasingly researched since the 1980 s, causing for its prominence in discussion of the issue. 
There is discrepancy among scholars, though, as not all disagree that the feminization of forced displacement is a new phenomenon that is increasing in its severity.

The feminization of forced displacement is an issue that spans across various academic disciplines of political science, social studies, and environmental studies, due to the multiple contributing factors. As a result of the concepts and insights coming from various disciplines, the study of refugees is interdisciplinary (Veney, 2007). In the past, gender has been on the periphery of migration studies (van Walsum and Spijkerboer, 2007, as cited in Gerard, 2014). Feminist scholars have brought research on gendered refugee issues to the forefront of the UNHCR and major refugee receiving countries (Edward, 2007). In terms of gender recognition in refugee studies, Giles (2013) states that prior to the 1980s there were 'genderless stereotypes' used to discuss and analyze refugees. Giles (2013) also states that feminist interest in this topic originated from the gender and development discipline, which was already examining the gendered poverty relations of the global North and South. In terms of the emphasis on the 'feminization' aspect of forced displacement studies, the field of feminist studies is the main source of research and literature. Other disciplines intersect with feminist studies, but the feminization of forced displacement is not researched solely through other disciplines.

\subsection{Literature Appraisal}

Some challenges have arisen in the literature available about the issue of the feminization of forced displacement. It is a challenge to find accurate statistics on how many forcibly displaced women are in need of protection, because very few sources focus only on women, and most sources include women and children in the same category. The accuracy of statistics is affected due to inconsistencies created by the two separate categories of 'women' and 'women 
and children' that are used interchangeably. Both women and children are nevertheless

vulnerable groups, but within the literature on this issue there lacks consistency for statistics on the respective categories.

As previously stated, much of the literature focuses on the 'feminization of migration' without a specific focus on the 'feminization of forced displacement'. There is a weakness in the existing body of literature on this particular issue, based on the fact that it is under-researched. The literature that focuses specifically on this phenomenon is strong in its conceptualization of the issue itself, though there are slight variations among scholars on their definitions of the feminization of forced displacement.

\subsection{Situating Research}

This literature review has been conducted for the purpose of situating my own research question in the existing research conducted on the feminization of forced displacement. My application of a conceptual framework based on feminist theory, examining the discourse of representations and how they frame the feminization of forced displacement, is significant because it is an area that has not been written about extensively. Analyzing this discourse is important in order to examine how the framing of forcibly displaced women creates essentialist representations of victims, which play a role in their protection under international documents and policies. Forcibly displaced women are discursively constructed in international documents and policies through the way in which knowledge is created about their gendered risks and protection needs. The existing literature mainly examines the way that gendered risks are created, the downfalls of policies such as gender-mainstreaming, and the ways that policies have been violated. What is largely missing from the literature reviewed is a critical discourse analysis 
addressing the way that UNHCR documents are conceptually framed by the terminology and language. I will address these gaps through the framework of my research question and methodology. 


\section{Methodology}

\subsection{Research Problem}

The feminization of forced displacement has occurred as a result of many political, social, and environmental factors. It is a phenomenon that occurs across the world, but women in some countries, primarily the Global South, are affected more than others as a result of conflict or lack of legal protection. Forced displacement affects women differently than it does men, which is an issue that has been addressed at the international level through by UNHCR, as seen in the UNHCR Handbook for the Protection of Women and Girls. While it is known that there are UNHCR documents to address the issues of gendered risk and protection needs, questions arise based on the discourse that constructs the representations of forcibly displaced women, which has consequences for their protection.

\subsection{Research Questions}

After identifying the research problem, I have formed the following research questions. How are UNHCR documents gendered to protect forcibly displaced women? How does the UNHCR Handbook for the Protection of Women and Girls frame the gender-based risks and needs of forcibly displaced women? How does the UNHCR Handbook for the Protection of Women and Girls contribute to the discourse on the representations of forcibly displaced women?

\subsection{Conceptual Frameworks}

The conceptual framework that will be used in my research paper is grounded in feminist theory and critical discourse analysis. As this research paper examines the representations through discourse for forcibly displaced women in terms of gendered risk and protection, being grounded in feminist theory is necessary in order to analyze gender inequalities and power 
relations. This feminist perspective "views as problematic women's diverse situations and the institutions that frame those situations" (Creswell, 2013, p. 98). The specific concepts and terms that inform my study are further explained in the Conceptual Framework section of this paper.

\subsection{Scope and Significance}

This study is significant due to the underrepresentation of the feminization of forced displacement in existing literature and research, in relation to the magnitude of the issue. The feminization of forced displacement is important to study due to the social implications of the large population of refugee and internally displaced women, as a result of the particularly gendered experiences of risk they may encounter.

The rise of globalization in the 1990s brought increased mobility and significant changes in the feminization of forced displacement, which subsequently required increased attention to issues of gendered risk and protection. A background of the international policies and documents pertaining to the protection of forcibly displaced women will be included in a later section of this paper in order to provide context for the creation of the UNHCR Handbook for the Protection of Women and Girls. In terms of scope, the critical discourse analysis will focus on the Handbook because it is the most recent international document specifically pertaining to my research questions.

This study will not address laws or policies regarding refugee status under the United Nations Convention for gender persecution, though this concept will be briefly discussed as an issue of the feminization of forced displacement. 


\subsection{Research Approach and Strategy}

My research approach is qualitative, through the research strategy of a critical discourse analysis that examines the UNHCR Handbook for the Protection of Women and Girls, by analyzing the linguistic constructs that contribute to the representation of forcibly displaced women. Creswell (2013) states that a qualitative research approach is used for "exploring and understanding the meaning individuals or groups ascribe to a social or human problem” (p. 32). The qualitative approach to this paper is based on the social and policy implications of the feminization of forced displacement in conjunction with the theories selected to analyze the discourse of forcibly displaced women in the chosen UNHCR document.

The Handbook is a qualitative document that provides extensive data on the vulnerabilities faced by forcibly displaced women. The Handbook will be used in order to examine how the discourse of the feminization of forced displacement is framed in terms of protection and gendered risk. The purpose of this critical discourse analysis is to add to the existing body of literature on both the feminization of forced displacement and also the most recent UNHCR document pertaining to the protection of forcibly displaced women. This document was chosen for the critical discourse analysis for a number of reasons. It is the most recent and significant document that the UNHCR has released on the issue of the feminization of forced displacement. In addition, the content of the Handbook addresses different aspects of the issue of the feminization of forced displacement, particularly with the focus on protection and gendered risk. Due to the substantial size of the document and the limits of the scope of this paper, the entire Handbook will not be analyzed. The section that is most relevant to the scope of my research is Chapter 1: Introduction to Protecting Women and Girls. This chapter was 
selected because its topic and content are aligned with the overall focus of this paper, whereas other chapters of the Handbook examine specific issues pertaining to the UNHCR activities in forced displacement contexts.

\subsection{Discourse}

Discourse is a mode of representation and a process by which an ideology is produced to become 'true' (Hall, 2007). Discourse is a way of talking, thinking or representing a certain subject (Hall, 2007), which is "produced and interpreted by human individuals interacting with one another" (Chilton, 2005, p. 23). Discourse achieves certain outcomes through the type of language that is used (Hart, 2008). It allows a topic to be constructed in a particular way, while also limiting the way it can be constructed (Hall, 2007). Discourse has consequences for those who exercise it and also those who are subjected to it, as it influences social practices (Hall, 2007). According to Foucault, discourse it is not ideologically neutral or innocent (Hall, 2007). When creating 'knowledge' about a certain subject discourse is political, purposeful, and ideological (Mohanty, 1988).

There are certain goals that discourse achieves, which is in the interests of the dominant power that creates the discourse. Discourse always operates in relation to power (Hall, 2007) and according to Foucault, discourse is "one of the 'systems' through which power circulates" (Hall, 2007, p. 57). Power is enacted through who controls the discourse and the ways that the creation of discourse serves their own interests. By engaging in a discursive practice that employs the dichotomy of "the West and the Rest", there is an imperialist Western superiority that is enabled

(Hall, 2007). The hegemonic discourse that constructs women comes from the cultural and historical contexts that are arbitrarily created (Mohanty, 1988). Discourse is influential by way of 
its power and dominance, which necessitates critical analysis in order to draw attention to underlying relations of power in seemingly neutral concepts.

\subsection{Critical Discourse Analysis}

In order to examine the discourse that frames the feminization of forced displacement, critical discourse analysis will be used in this paper to examine linguistic constructs. The use of critical discourse analysis is necessary to address implications from the way language is used to perpetuate certain ideas about certain groups. There is no one type of critical discourse analysis, but it is common that all types reject the idea that language is a neutral way of reflecting or describing the world (Gill, 2000). Critical discourse analysis is a "variety of different approaches to the study of texts, which have developed from different theoretical traditions and diverse disciplinary locations" (Gill, 2000, p. 172). Critical discourse analysis examines the historical, social, and political contexts beyond focussing on language. (Baker, Gabrielatos, Khosravinik, Krzyżanowski, McEnery \& Wodak, 2008). Social science discourse analysis is critical about the way knowledge is taken for granted because knowledge is socially constructed (Gill, 2000). It looks at the way power relations and dominant influences unfold in discursive practices, which contributes to socially constructed prejudice (Baker et al., 2008). This framework of critical discourse analysis will be used to inform the research of this paper.

\subsection{Coding}

The critical discourse analysis of the Handbook looks at keywords, phrases, and the way linguistic constructs frame issues of protection for forcibly displaced women. In order to identify the key terms and phrases in the critical discourse analysis, the practice of coding will be used. Codes are used to identify themes or categories for qualitative research (Creswell, 2013). The 
systematic steps of coding include: generating categories of information, selecting categories and situating them in a theoretical model, and developing a story from the interconnections of categories (Creswell, 2013). These three systematic steps are central components of the critical discourse analysis in this paper.

There are four distinct categories of coding that are used in this critical discourse analysis. Each category is directly related to components of the conceptual framework, which are: the gender binary, the discourse of victimization, gender and cultural essentialism, and global feminism. In overview, the four categories of coding are the binary of gender relations, terms contributing to the discourse of victimization, the construction of absolute terms and relative terms, and lastly the use of pronouns that signify the Western perspective.

More specifically, the first coding category examines the gender binary relational aspects of the feminization of forced displacement, which contributes to the discourse of social constructions of gender. The second coding category is used to analyze the construction of the discourse of victimization for forcibly displaced women based on the 'positive' or 'negative' characteristics used to describe them. The third coding category looks at the construction of 'absolute' terms and 'relative' terms that are used to describe the type of experiences or prevalence of these occurrences for forcibly displaced women, which is related to gender and/or cultural essentialism. The fourth category of coding identifies the pronouns that signify the Western perspective in the document and will be examined through the distinctions between global feminism and postcolonial feminism. These four categories were in part conceptualized before approaching the critical discourse analysis but were also in part formed after reading 
through Chapter 1 of the Handbook. Thus, a mixture of predetermined codes and emergent codes were used.

\subsection{Researcher Self-Disclosure}

As a researcher, I have a certain bias that I bring to the study based on my identity and position in society. As a female, my gender allows me to identify with some of the inequalities that women experience. Gender also plays a role in my interest for researching the impact of discursive practices and policies on forcibly displaced women, as I critically analyze issues and situations through a feminist lens which views many issues as being rooted in patriarchy. I am aware that feminism in the Global North differs from feminism in the Global South, therefore as a white Canadian woman, the feminism within my conceptual framework is more aligned with global feminism. It is important that my own experiences do not impede my conceptual framework of the feminist perspective. Acknowledging my position does not take away my bias, as research is never objective, but it allows my stance to be situated based on my social position. My interest in the representation of forcibly displaced women was sparked through my personal relationships with women who came to Canada as refugees. The refugee women that I have developed friendships with have diverse experiences and backgrounds. Yet, during social interactions that I observed, they were treated by others as if they are victims without agency, and having the same trauma or experiences as a result of their gender and culture. I question how these representations are constructed through discourse and the impact that this has on the treatment of refugee women both in Canada and at the international level. These personal encounters have shaped my perspective on this topic. As a researcher, it is important that I 
disclose my perspective at the entry point of this research paper, as it shapes the way I have chosen my conceptual framework and applied these concepts. 


\section{Conceptual Framework}

The conceptual framework in this paper is a number of concepts that are linked together and inform the research. It is the theoretical lens through which I will conduct my research and analysis and has been formed based on the concepts that pertain to the argument of this paper. Feminist theory informs my conceptual framework, as it examines gender inequalities pertaining to the representations of the experiences of forcibly displaced women. This conceptual framework has informed the methodology by framing the critical discourse analysis through the construction of representations based on the following: the construction of gender, gender essentialism, cultural essentialism, representations of victims, the discourse of victimization, and Western feminism. These concepts will be further explained in the subsequent sections.

\subsection{Construction of Gender}

The construction of gender as a binary is an important component of my conceptual framework, as it sets the foundation for demonstrating the way that these concepts are rooted in gender relations. Gender is described as "identities, relations, and ideologies that are fluid, not fixed" (Mahler and Pessar, 2006). Gender is conceptualized by Cohn (2013) as being constructed through a process where humans are divided into the categories of male and female that have traits, characteristics, and meanings attached to them. The relationships between women and men are based on the socially or culturally constructed characteristics that are assigned to each sex (Gusman, 2013). In the hierarchy of power relations, feminine categories are systematically placed in a secondary role (Laviolette, 2007). By deconstructing these categories and relationships it is possible to gain an understanding of the relations of power and the process of construction (Indra, 1993). It is clear that the social construction of gender divides men and 
women into categories with corresponding roles and traits, often which are generalized to create essentialist ideas about broad groups. These definitions of the gender binary serve to polarize the categories of men and women.

Gender should be defined as a socially constructed concept in order to display the genderspecific factors that hinder certain rights (Laviolette, 2007). The feminization of forced displacement is caused by factors which are tied to gendered discrimination (Gusman, 2013). Gusman (2013) states that "the social positioning of women and men is affected by political, economic, cultural, social, religious, ideological, and environmental factors and can be changed by culture, society, and community" (p.433). It is not the biological sex of that causes genderbased risk, but rather it is the power relations that constitute relations between men and women (Laviolette, 2007). Therefore, there are possibilities for change through critical discourse analysis of the way these social constructions are produced and reproduced.

In this conceptual framework, gender is seen "both as a key relational term and as a context, both culturally and historically specific" (Edward, 2007, p. 44), which contributes to the deconstruction of refugee experiences of universality and homogeneity (Edward, 2007). Gender analysis should not be undertaken in isolation from other structural determinants; but rather an intersectional analysis approach should be taken (Gerard, 2014). Using an intersectional approach avoids fixed categories or the act of universalizing because it includes the "structural factors such as race, class, disability, sexuality, and others as they arise" (Gerard, 2014, p. 10). In conclusion, the concept of gender will be discussed as a socially constructed binary that intersects with multiple systems of oppression. This definition will be used to examine gendered power relations, inequalities, and discrimination that forcibly women face. 


\subsection{Essentialism}

Essentialism is a concept of contention due to the way it constructs categories based on generalizations about characteristics or qualities. An essentialist outlook holds the assumption that individuals with certain characteristics, such as gender or race, have experiences which are "constant through time, space, and difference historical, social, political, and personal contexts" (Grillo, 1995, p. 19). Essentialist generalizations can both enable and cause theoretical perspectives or political agendas to remove the concerns of many women that are marginalized through their class, race, ethnicity, and sexual orientation (Narayan, 1998). Essentialism creates 'discourses about difference' that present differences about certain groups as being 'real', by covering up the way that they are produced and reproduced through discourse (Narayan, 1998). When these notions about certain groups are considered 'real', they become embedded in society and alter the way individuals are viewed, as a result of being categorized as part of generalized groups. This process occurs because engaging in the process of essentialism is easier than it is to "develop the tools for understanding gender oppression across cultures and politics" (Razack, 1996b, p.173). It is clear that the pervasiveness of essentialism in society is problematic. In addition to the broader concept of essentialism, I will discuss the processes of both gender essentialism and cultural essentialism, as they pertain to representations of forcibly displaced women. In overview, gender essentialism "often proceeds to assume and construct sharp binaries about the qualities, abilities, or locations of 'men' and 'women' [while] cultural essentialism assumes and constructs sharp binaries between 'Western culture' and 'non-Western cultures"” (Narayan 1998, p.88). These two processes will be further examined in regards to the way discourse can essentialize forcibly displaced women based on their gender and/or culture. 


\subsection{Gender Essentialism}

The binary concept of gender can be essentialized by imposing certain experiences and characteristics onto all women, simply because they are women. Within feminist literature, research on the entire category of women poses the risk of trivializing or masking differences within this broad group (Indra, 1993). Representations of the 'universal woman' suggests that women have a collective commonality, which comes from biological essentialism (Indra, 1993). There is a homogeneity employed when discussing women in literature, which is that women are "characterized as a singular group on the basis of a shared oppression" (Mohanty, 1988, p 65). Assumptions are made that women are a "coherent group with identical interests and desires, regardless of class, ethnic or racial location" (Mohanty, 1988, p. 64). Gender essentialism also perpetuates the view of women as a "coherent group across contexts [...] [which] structures the world in ultimately binary, dichotomous terms, where women are always seen in opposition to men, patriarchy is always necessarily male dominance, and the religious, legal, economic and familial systems are implicitly assumed to be constructed by men” (Mohanty, 1988, p. 78).

A feminist critique of gender essentialism challenges the essentialist claims about women as over-generalizations. It also states that these generalizations are hegemonic in terms of their representation of 'women's issues' being the problems of privileged women who are commonly white, Western, middle-class, and heterosexual (Narayan 1998). There is a need for gender to be discussed in relation to issues of class, race, ethnicity, and sexual orientation in order to "avoid essentialist generalizations about 'women's problems"” (Narayan 1998, p.86). Avoiding hegemonic gender essentialism can be accomplished by taking into account the differences among women, based on these aforementioned factors (Narayan, 2000). 
In the area of forced displacement studies, concepts of gender can be essentialized, putting women at further risk than they already are (Grabska 2011). There are essentialist views of gendered social positions that become apparent as men are viewed as the protector of the women and children who are seen as vulnerable and weak (Laviolette, 2007). This process of gender essentialism exists for constructions of men and women in general, but in addition, it also occurs in the gender divisions of forcibly displaced persons. This process is also evident in that "essentializing women are seen as peacemakers, as more peaceful, victims of gender-based violence, vulnerable to subordination, without access to rights, disadvantaged and at risk missed more complex gender mainstreaming arrangements" (Grabska, 2011, p. 90).

\subsection{Cultural Essentialism}

Narayan (1998) argues that feminist attempts to avoid gender essentialism often results in perpetuating cultural essentialism. Essentialist views of culture are conceptualized by Narayan (2000) as 'package picture of cultures', which understands cultures as being sharply defined from others and having distinct contents. This view of culture also prescribes that there are no differentiations within the cultures themselves; they are homogenous and all-encompassing. Thus, through the standpoint of cultures being distinct and static, cultural essentialism is enabled.

The process of 'othering' within Edward Said's (1979) theory of Orientalism is a form of cultural essentialism. 'Othering' is an activity by which undesirable traits are attached to certain groups and a hierarchy is created between the 'self' and the 'other' (Said, 1979). Discussions of culture are often heard by dominant groups in ways that make 'other' cultures appear inferior

(Razack, 1996b). When forcibly displaced women are culturally essentialized there is a process of 'othering' that occurs as a result of the women being placed in a category of imposed 
characteristics based on ideas about their culture. These ideas are based on a lack of understanding and viewing non-Western cultures as being inferior, which is evident in refugee hearings when adjudicators "sort out details of persecution from stereotypical messages of inferior cultures" (Razack, 1996b, p. 173). There are both differences and similarities among forcibly displaced women based on the factors of their race, culture, class, age, and nationality (Indra, 1993). In spite of their diverse backgrounds, forcibly displaced women share some commonalities in their experiences of escaping dangerous circumstances (Lee, 1989). It should not be disregarded that forcibly displaced women have meaningful commonalities both within and across cultures and gender, yet it is also beneficial to understand how and why parallels are formed among large groups of individuals and the consequences of these generalized perceptions (Indra, 1993).

\subsection{Representations: Victims}

Writing about the experiences of forcibly displaced women can be essentialist and create representations that portray them as victims. The representation of forcibly displaced women can be a double-edged sword. Portraying them as vulnerable victims can reflect the significant challenges of their situation, but this portrayal can also make them appear as being unable to adapt or cope with their situations (Moussa, 1998). Focussing on the vulnerability of forcibly displaced women places the problem on the women themselves, rather than placing the problem on the discrimination that is enacted against them because they are women (Moussa, 1998). The discourse that spreads the essentialist representations of forcibly displaced women as victims without agency is conducted in multiple ways. Representational discourse causes the victimization of forcibly displaced women through the way they are spoken about and their 
visual depictions (Johnson, 2011). There have been gender assumptions perpetuated in refugee policy about women's “inherent vulnerabilities and innocence" (Johnson, 2011). Disputing the gender constructions which contend that women have inherently vulnerable qualities does not mean that there should be a disregard for the particular vulnerabilities that women may experience. Undoubtedly, women are at a higher risk than men of encountering sexual and gender-based violence and discrimination due to their social positioning that enables this oppression. While these vulnerabilities are evident in certain situations, when discussing the experiences of forcibly displaced women there must be the opportunity for variations and differences in their situations.

The current portrayals of refugees are as nameless and voiceless victims without any agency (Johnson, 2011). This portrayal of forcibly displaced women is not of an individual that is resilient or empowered, but rather as a nameless figure that represents a large and diverse population. Hyndman and Giles (2011) state that researchers and writers contribute to producing and reproducing voiceless and passive refugees by representing them as being helplessly in need of solutions to their problems. Humanitarian activities tend to silence refugees, as they cause refugees to become general victims rather than individuals (Malkki, 1996). National and international organizations have the control over the speechlessness of forcibly displaced persons (Malkki, 1996). This constructed representation of helplessness for refugee women is linked to their speechlessness because 'helpless victims' are in need of protection and also in need of someone to speak for them (Malkki, 1996). McPherson (2014) states that there is "a propensity [in forced displacement studies] to represent refugees in essentialist ways, the hegemony of trauma as the major articulation of refugee suffering being an example of such essentialist 
representation" (p. 3). The representations of forcibly displaced women as victims are constructed in ways that are directly linked to the discourse of victimization.

\subsection{Discourse of Victimization}

The discourse of victimization is perpetuated through the way that identities and representations of forcibly displaced women are reduced to their experiences of forced displacement. The intersections of culture and gender are prominent in the conceptualization of the discourse of victimization as a result of the essentialism of refugee women's experiences. Though not the only factors of victimization, the implications of gender and cultural essentialism contribute to the negative representations of forcibly displaced women as being victims without agency. The discourse of victimization maintains Western hegemony and oppression against forcibly displaced women.

The discourse of victimization is enabled through the dichotomy of two categories for forcibly displaced women: a vulnerable victim or a survivor with agency. The concept of agency is "to validate the ability of actors to consult with the situation and others, and negotiate these contexts actively, even if they are unable to manipulate structure to coincide with their subjective needs" (Rider, 2012, p.84). In terms of the victim side of the dichotomy, Razack (1998) describes a process of construction "when women are defined by what is done to them, rather than what they do as social actors" (p. 98), which directly applies to the way that forcibly displaced women are viewed based on their oppressions they face in gender and culture. Feminism has influenced the misrepresentation of agency within refugee studies, as the characterization of victimization is prevailing in so many accounts of how refugee stories are represented (Indra, 1993). The discourse of victimization of forcibly displaced women manifests from the intersection of gender 
and cultural discrimination in their representations as discourse about women from the Global South reduces them to ideas about their culture and their position as women. On the contrary, this discourse constructs Western women as having agency based on ideas that they are liberated within their culture. This discourse of victimization comes in part from Orientalism, as the discourse is constructed through the dominant Western perspective as a result of policies and documents being produced from the West. According to Akram (as cited in Hajdukowski-Ahmed et al., 2013), in the asylum and refugee context there is a 'new Orientalism' which threatens accurate representations of victimization. This concept will be further explained the in next section on the role of global feminism.

\subsection{Global Feminism}

Global feminism and postcolonial feminism are two particular feminist perspectives that examine issues through different lenses. In order to avoid creating a theoretical binary, it is important to state that these feminist perspectives exist on a spectrum rather than being polarized. The global feminist discourse enables power relations that are "structured in terms of unilateral and undifferentiated source of power and a cumulative reaction to power" (Mohanty, 1988, p. 79). Postcolonial feminism asserts that "feminism is not universal and unifying, rather,

there are diverse, historicized, and context-specific forms of feminism” (Edward, 2007, p. 53). Postcolonial feminism came out of a critique of global feminism and it acknowledges the differences among diverse groups of women in order to address the universalism and over simplification of global feminism (Mohanty, 1988). These perspectives are not based on location but reflect ways of thinking about women and from issues that pertain to women are viewed and addressed. 
The intent of global feminism is not necessarily negative, but rather it is the outcome that is problematic due to the practices of essentialism and 'othering'. Postcolonial feminists need to be careful about essentialist contrasts between Global North and Global South cultures (Narayan, 1998) because this does not account for the fluidity of culture. Forcibly displaced women from the Global South are essentialized by Western women through the process of 'othering'. The global feminist employs certain categories in their relationships with the Other (Mohanty, 1988). Global feminism is knowledge produced in the West by "privileged, white, middle-class, and heterosexual women" (Edward, 2007, p. 52). Thus, global feminism refers to a way of knowing and acting, rather than bodies or individuals.There are particular analytic categories used in creating knowledge about the 'Third World Woman' which are rooted in economic and political hierarchies of colonization and due to which some women are produced through the discourse in global feminist writing as a 'singular monolithic subject'(Mohanty, 1988). There is a dichotomy of the 'Third World woman' as sexually constrained, ignorant, poor, indication, domestic, and victimized; while the 'Western woman' is thought of as educated, modern, controlling her own body and sexuality, with the freedom to make her own decisions (Mohanty, 1988). Global feminists appropriate 'third-world difference' as something that oppresses the women in countries of the Global South, which serves to characterize their lives (Mohanty, 1988). There is a need for global feminist perspectives which take into account the differences among women in order to avoid essentializing analysis of concerns of women in the Global South (Narayan, 1998). Making the static distinctions of cultures can stratify gender and cultural essentialism by positioning Western and non-Western groups as opposites based on their differences, through global feminism. 


\section{Critical Discourse Analysis of the UNHCR Handbook}

The UNHCR Handbook for the Protection of Women and Girls is a document that was created as a tool to achieve the empowerment of displaced women and girls through the promotion of gender equality (UNHCR, 2008). In the introduction of the Handbook, it states that the document "describes some of the protection challenges faced by women and girls of concern to the Office of the United Nations High Commissioner for Refugees and outlines various strategies [that the UNHCR] should adopt with [their] partners to tackle these challenges" (UNHCR, 2008, p. 1). There are a total of six chapters in the Handbook, which are as follows: Chapter 1: Introduction to Protecting Women and Girls, Chapter 2: Principles and Practices for Gender Equality, Chapter 3: Identification, Prevention, and Responses to Risks Faced by Women and Girls, Chapter 4: UNHCR's Protection Response, Chapter 5: Exercising Rights and Ensuring Protection, and Chapter 6: The International and Regional Legal Framework. As stated previously, the section that is most relevant to the scope of my research is Chapter 1: Introduction to Protecting Women and Girls, because it's topic and content is aligned with the overall focus of this paper, whereas other chapters of the Handbook examine specific issues pertaining to the UNHCR activities in forced displacement contexts.

Each section of this critical discourse analysis has been created based on categories of codes. Within these categorical sections, there are also more specific sections analyzing the key terms and their underlying meanings. The first section 'Binary of Gender Relations' examines how the gender binary is constructed through the Handbook's mention of men/boys and women/ girls. The second section 'Terms Contributing to the Discourse of Victimization' analyzes terms that could have positive or negative impacts on the representation of forcibly displaced women, 
depending on how they contribute to the discourse of victimization. The third section

'Construction of Absolute Terms and Relative Terms' applies the concepts of gender essentialism and cultural essentialism to analyze how certain terms acquire 'absolute' or 'relative' meanings in their representations of forcibly displaced women. The fourth section 'Western Perspective' examines the stance of the UNHCR Handbook based on its use of certain pronouns and their connotations of global feminism and Orientalism. Excerpts from the Handbook are provided in each sub-category as examples and evidence for the critical discourse analysis. All of these excerpts come from Chapter 1 of the Handbook and have been selected through the process of coding. The purpose of this critical discourse analysis is to examine the way that the discourse of the UNHCR Handbook for the Protection of Women and Girls frames the issue of the feminization of forced displacement in its representation of forcibly displaced women and the implications for the treatment of forcibly displaced women in society.

\subsection{Binary of Gender Relations}

The first coding category examines the statements that frame gender and gendered protection issues as relational between women/girls and men/boys. Consistent with the conceptual framework, the gender binary of the relationships between women and men based on the socially or culturally constructed characteristics that are assigned to each is used in this analysis (Gusman, 2013). The statements that make reference to men/boys were identified in terms of their mention of UNHCR work that has been conducted with both genders and taking the gender relations into consideration for the creation of the need for protection as forcibly displaced women. This critique is related to the way in which the construction of gender in discourse is occurring, as it contributes to the power relations being part of a gender binary. 


\subsubsection{Gender Relations}

The approach of the Handbook to societal change in terms of gender relations is exemplified in this section:

By focusing also on men and boys, as well as institutions, policies, and programmes, it holds great potential for societal change. It clearly recognizes that gender equality can only be achieved through partnership between women and men (UNHCR, 2008, p. 13).

Gender equality is not a 'women's issue' but should concern and fully engage men as well as women (UNHCR, 2008, p. 12).

Simply including the words 'men/boys' in the Handbook is a discursive practice concerning gendered issues because it shows that gendered issues are not just women's issues. Not only does this demonstrate that men/boys contribute to gendered protection issues, but it also shows that the inclusion of men/boys in the protection of women/girls is of importance. The language that includes discussion of both sides of the gender binary fits in with the movement from Women in Development in the 1970s to Gender and Development in the 1980s (Rathgeber, 1990). Addressing gender inequality was first taken by the Women in Development approach, but this was flawed because it focussed on women's experiences and perceptions as separate issues (Rathgeber, 1990). There was the movement to a Gender and Development approach, which questions the relations between women and men and the social structures which create inequality (Rathgeber, 1990). The Handbook takes on the Gender and Development approach through its inclusion of men/boys in the discussion on gendered protection issues. The discourse puts forth that it is not only a women's issue because they are most directly affected, but rather that it is also a men's issue because they affect it directly. Regardless of these intentions of displaying gender relations, which are often positive, these constructions re-inscribe that very binary that in 
the first place enable the social and cultural conditions that oppress women. It gives the underlying assumptions that men are perpetrators and women are victims, which is evident in Grabska (2011) stating that there is a simplified view of refugee women as victims or survivors while men are viewed as perpetrators and violators. A gender-neutral discourse is not being argued for here, as feminist theory argues that all discourse should be gendered, but rather it is being argued that the way in which language in this section of the Handbook contributes to the construction of a gender binary.

\subsubsection{Engagement of Men/Boys}

The Handbook refers to one of the implementation challenges as being caused by a lack of engagement with men and boys by stating:

We have often failed to work in partnership with men and boys in promoting gender equality. Yet change will only occur by also working with men and boys in the communities with whom and for whom we are working (UNHCR, 2008, p. 18).

The construction of women is in part based on the intersections of different contexts that are simultaneously imposed upon them. Not only do the gender relations of forced displacement need to be understood, but also the gendered relations of humanitarianism needs to be challenged in terms of the way in which women are receiving protection and assistance (Giles, 2013). The inclusion of 'men and boys' in the language that is used to describe failures in the implementation of humanitarian programs by the UNHCR is necessary in order to display power relations and the construction of gender roles. The opposition of males in the communities that the UNHCR works with is largely rooted in socially constructed gender roles that create barriers to women's upward mobility in gaining protection. The approach to engaging men/boys in 
humanitarian programs is problematic in its reinforcement of the gender binary because it constructed the underlying meaning that there is a tension between the interests of each side.

\subsubsection{Gendered Power Relations}

Certain statements referring to gender relations display the disadvantage that women may experience as a result of the power relations being enacted:

Men are usually also better placed to be involved in, and benefit from, reconstruction initiatives because of their greater control over economic resources, access to education, and participation in public life before the conflict (UNHCR, 2008, p. 6).

Women and girls generally have fewer opportunities, fewer resources, lower status, and less power and influence than men and boys (UNHCR, 2008, p.12).

The language used in these statements is important because there is a comparative frame of reference provided for why forcibly displaced women face discrimination and risk; it comes through unequal power relations with men. It is significant that the disparities women face are not discussed in isolation, but rather that they are identified as being tied to the distribution of protection and human rights that men experience, which puts women in a lower position. There is evidence of a cyclical process of power relations being inherent to the gender binary, but using the gender binary language in this discourse also reinforces the gender binary.

The underlying meaning of this discourse of inclusion for men/boys and women/girls creates a complex continuum, which benefits forcibly displaced women while it also reinforces the gender binary. It benefits women by displaying the relationship between gender in terms of inequality and oppression, showing that the disadvantages for forcibly displaced women are not isolated 'women's issues'. But this clearly reinforces the gender binary because there are only two distinct categories without any fluidity of experiences or positions. It creates pre-determined false expectations about gender characteristics and those that are supposed to fit into. The 
construction of a gender binary is problematic because it places women in a distinct category and does not allow for the possibility of the spectrum of characteristics that women may embody. A gender binary does also allow for women to be recognized as a separate group with certain needs, though, which is necessary for their protection. This analysis prompts questions about how discourse can avoid reinforcing a gender binary without becoming completely gender-blind and/or gender-neutral.

\subsection{Terms Contributing to the Discourse of Victimization}

In this section, certain terms that contribute to the discourse of victimization have been identified. These terms have been highlighted based on how they relate to the representations of forcibly displaced women's experiences. This section of the critical discourse analysis not only looks at the keywords but also the context of the statements and how the entire statement are made in conjunction with the other words, to create linguistic constructs.

\subsection{1 'Empowerment', 'Victim', and 'Survivor'}

This notable excerpt from the Handbook of this code is about the use of multiple coded terms including “empowerment", "victim”, "survivor”, "challenges”, and "obstacles":

At the same time, despite all these challenges, women and girls of concern show great resilience, resourcefulness and courage in adapting to and surmounting these problems. They may too often become victims of serious human rights violations, but they are also strong survivors whose active participation and empowerment we must support and secure if we are to protect their rights and those of their communities (UNHCR, 2008, p. 11).

Empowerment is a highly gendered process (Parpart, Rai, and Staudt, 2003). The use of 'empowerment' is seemingly a positive word that focuses on support. It is linked to the characteristics of strength and autonomy, which exemplify the element of the resilience of forcibly displaced women. It also raises questions about who grants empowerment for the 
women discussed in this context. As Parpart et al. (2003) point out, "understanding and facilitating women's empowerment requires a more nuanced analysis of power" (p. 4). The term 'empowerment' is used in a discourse of power relations in terms of the UNHCR programs that provide a platform for forcibly displaced women, with the assumption that they cannot be empowered by their own efforts. Parpart et al. (2003) also state that "groups become empowered through collective action, but that action is enabled or constrained by the structures of power that they encounter" (p. 4). In order to empower, there must be the "ability to exert power over" (Parpart et al., 2003, p. 5).

Empowerment has also been linked to colonial notions of the West enabling the East. Within the discourse of empowerment for women, there is a move from 'victim' to 'survivor'. However, it's effectiveness is challenged by postcolonial feminists such as Kapur (2002), Parpart et al. (2003), and Hajdukowski-Ahmed et al. (2013), because it reinforces a dichotomy between 'victim' and 'survivor', whereas women may occupy multiple positions in different sites. Empowerment is a historical and imperialist term since it relates to structures of power within a particular context, in this case, women of the Global North and women of the Global South (Parpart et al., 2003). The intersections of oppression that forcibly displaced women face within power structures puts them further under the control of power structures that are rooted in patriarchy, and in the case of the Handbook, they are rooted in a Western perspective. The use of the word 'empowerment' serves to reinforce the power relations of the discourse of victimization.

The dichotomy of the 'victim' vs. 'survivor' is reinforced in this excerpt from the Handbook. The underlying meanings behind these linguistic constructs are necessary to analyze 
for further understanding of the discourse of victimization because it has negative implications for the representation of forcibly displaced women. The Western representation of women in forced displacement situations is a victim without any agency and "refugee women and girls have become the face of refugee victimhood" (Johnson 2006; Pupavac 2008, as cited in McPherson 2014, p. 4).

Kapur (2002) states, "the victim subject has reinforced gender essentialism and cultural essentialism" (p. 2) and furthermore "women in the Third World are portrayed as victims of their culture, which reinforces stereotyped and racist representations of that culture and privileges the culture of the West" (p. 6). Kapur (2002) uses the term 'victim subject' to avoid the dichotomy of the 'victim' vs. survivor'. Particular representations of forcibly displaced women tend to essentialize them by perpetuating their victimization, and therefore such representations facilitate their discrimination because their protection needs are addressed based on one homogenized 'truth' about the characteristics of their gender and culture. There is a strong link between the ways that marginalized groups are represented and the types of policies that are created to govern them (McPherson, 2014), which is why the discourse of victimization has problematic implications. This critical discourse analysis does not challenge the fact that populations of forcibly displaced women include individuals that have been victimized in many ways and are in need of urgent protection (Malkki, 1996), as this is true, but rather it tackles the underlying meanings of the discourse of victimization. The discourse of the Handbook reinforces a dichotomy of the victim object and the survivor subject. Hajdukowski-Ahmed et al., (2013) state that "two or more seemingly incompatible positions can cohabit and function alternatively in different contexts, such as that of a victim and survivor" (p. 49), in a critique of the dichotomy 
between the victim or the survivor. There is the essentialized victim on one side and then the empowered survivor on the other side of the dichotomy. As Kapur (2002) puts it, "the creation and reinforcement of a victim subject has not empowered women" (p. 36). As discussed previously, the discourse of empowerment is deeply embedded in power relations.

The mention of the word 'survivor' on the other hand signifies a move away from the discourse of victimization and towards a representation of resilience and strength. It signifies a level of agency in the representation of forcibly displaced women because they have been able to exceed the oppression of victims. It validates the situations of individuals to negotiate their contexts even if they are unable to alter the structures that oppress them (Rider, 2012). But, though it is portrayed as being one side of the dichotomy in the above Handbook excerpt, the survivor discourse is very much embedded in the power relations similar to those of the empowerment discourse. The underlying meanings in the use of the term survivor in the Handbook are based on how they are supported and empowered by others.

The UNHCR and aid agencies must change their thinking of refugee women as 'vulnerable' which informs their thinking and programs which reinforce this stereotype (Hajdukowski-Ahmed et al., 2013). Women are unable to reduce their vulnerability because of the lack of validation for their experiences of victimization and lack of autonomy from the international system (Rider, 2012). Forcibly displaced women are victimized when they are described by the oppression they experience within the international system, rather than their own actions in relation to the international system, which is related to the empowerment discourse. The implications of representations of forcibly displaced women as victims further marginalizes and oppresses them in terms of the policies and documents determining their 
protection, that 'save' them and subsequently take away their agency. The process of essentialism shapes the discourse of the UNHCR Handbook pertaining to the way that forcibly displaced women are framed, as a discourse of victimization negatively portrays their experiences.

\subsection{2 'Challenge' and 'Obstacle'}

Another dichotomy evident in the discourse of the Handbook is the use of 'challenge' vs. 'obstacle':

Once home, women and girls may face obstacles accessing their housing, land or property, education, and other essential services (UNHCR, 2008, p. 11).

Particular challenges can arise in the following situations: urban areas, camps, isolated noncamp areas, upon return, upon local integration, upon resettlement (UNHCR, 2008, p. 9).

The term 'obstacle' signifies a barrier in place that prohibits forcibly displaced women. The underlying meaning of the term takes away autonomy and resilience within systems of oppression that discriminate against them for the activities of obtaining services or gaining an education, in addition to the social, political, and cultural constructs in the way of women's wellbeing. Contrarily, the term 'challenge' describes the way forcibly displaced women deal with discrimination. It acknowledges that there are additional issues that forcibly displaced women experience as a result of their social position in society, but has the positive element of being an issue that can be overcome. The latter excerpt also discusses the way that challenges arise in certain situations, which displays the intersectionality of oppressions depending on the context.

\subsection{3 'Risk'}

The term 'risk' is another important component of the discourse of victimization, as evident in the following statements: 
In collective reception centres, women and girls on their own may also be at risk of further abuse or violence, if they are not accommodated separately from men or if there is not sufficient privacy (UNHCR, 2008, p. 8).

Internally displaced women and girls living in remote areas are also more vulnerable to armed attack by raiders and are at heightened risk of abduction, rape and sexual abuse (UNHCR, 2008, p. 10).

The underlying meanings in the use of the term 'risk' are dependent on the additional constructs of the rest of the statement. The way that risk is written about in the Handbook is in a way that states in different situations, different women may be at risk to types of exploitation, violence, or oppression. It is clear in the discourse of the Handbook that relations between men and women are linked to gendered risk, which demonstrates that gendered risk that forcibly displaced may face are not isolated. The discourse about gendered risk must include the factors as to why forcibly displaced women are in need of increased protection, which is as a result of male perpetrators and their lower position in society before a conflict. Pre-existing gender discrimination within societies is intensified in the situations of forced displacement (Gusman, 2013). Forcibly displaced women are constructed in this discourse based on what is done to them instead of what they do as social actors (Razack, 1998). Risk enhances the notion of 'survivor' and 'victimhood' through the element of vulnerability, based on whether or not an individual is viewed as vulnerable to the risk they may face. Within the construction of 'risk', there are the underlying determinants of resilience or vulnerability being directly linked to the construction of a survivor or a victim. The discourse of victimization is evident here, as the gendered risk for forcibly displaced women are being represented as attached to vulnerability, rather than resilience or agency. 


\subsection{Construction of Absolute Terms and Relative Terms}

It is the way in which certain terms are given meaning in the discourse of the Handbook that gives them 'absolute' or 'relative' meanings. These terms have not been identified for analysis because they have intrinsic meanings themselves, but underlying meanings attached to them through what is said and also what is left unsaid in the discourse. These terms also acquire meaning with other words that are part of entire statements. The category of 'absolute' is based on terms that have the connotation of applying to all women or the majority of women. The 'absolute' terms contribute to essentialist views of forcibly displaced women because they do not leave room for variations and they speak in definitive terms. On the contrary, the category of 'relative' is based on an openness and ambiguity formed in statements about the experiences or situations of forcibly displaced women, allowing for variations in their representations. The 'relative' terms do not contribute to an essentialist representation because they allow for multiple possibilities depending on the context.

\subsection{1 'Often', 'Generally' and 'Usually'}

The way in which the Handbook uses the terms 'often', 'generally', and 'usually' fails to capture specificity or go beyond a broad conceptualization of the issues that forcibly displaced women face, thus acquiring 'absolute' meanings:

Often, they must spend their time doing domestic chores or may be married off as children and become teenage mothers (UNHCR. 2008, p. 6).

When they return home, for instance, after a conflict has ended, they usually face still more obstacles to resuming a normal life (UNHCR, 2008, p. 7).

Women and girls generally have fewer opportunities, fewer resources, lower status, and less power and influence than men and boys (UNHCR, 2008. p. 12). 
The terms 'often', 'generally' and 'usually' are used in a manner that creates an essentialist discourse because can be interpreted as being applicable to everyone to which it refers. The underlying meanings of these terms evoke essentialist assumptions because it makes it appear that the majority of forcibly displaced women have this experience and this creates a discourse of one generalized representation that is assumed to depict the majority. The lack of distinction of forcibly displaced women as individuals produces a discourse that these representations of victims cover all forcibly displaced women, which is perpetuated by essentialism. Though these terms appear to be used interchangeably, the message of absolute applicability and subsequent essentialist discourse is only perpetuated in certain statements depending on the language used to acquire essentialist meanings.

The underlying meanings of these absolute terms of 'often, 'generally', and 'usually' does not allow for the discourse to be inclusive of the context for the extent of those affected or different experiences they may encounter. The inclusion of these terms with descriptions about experiences of forcibly displaced women contributes to creating generic statements that frame representation of those affected by the feminization of forced displacement as a broad group that can be dealt with in the same way. When forcibly displaced women are put into such general and unspecific terms, the discourse from UNHCR documents dehumanizes them. Essentialist discourse also dehumanizes women through creating a mass representation supposedly speaks for the experiences and situations of forcibly displaced women. Forcibly displaced women are culturally essentialized as one homogenous group which results in silencing the experiences of marginalized women. It takes away the variations among humans lived experiences, social, contexts, and the intersections of race, gender, ethnicity, age, education. Thus, the essentialist discourse through terms such as 'often, 'generally', and 'usually' with the underlying meanings 
of unspecific representations about the experiences of forcibly displaced women is problematic and further marginalizes them.

\subsection{3 'Are' and 'Can'}

Another area of concern is the way in which saying 'are' is used in an 'absolute' way to describe the situations of forcibly displaced women as opposed to the 'relative' way of saying 'can':

As financial resources are depleted, adolescent girls are married off at increasingly younger ages (UNHCR, 2008, p.10).

The impact of forced displacement on women and girls can be devastating (UNHCR, 2008, p. $9)$.

The way the Handbook uses 'are' contributes to (re)producing a discourse about the 'truth' because it reinforces underlying meanings of absoluteness in experiences and subsequently representations. Whereas using the word 'can' provides some relativity for the situations being discussed, based on those involved and the level of impact they experience. There are 'discourses about difference' created through essentialism, which cover up the processes and ways that differences among certain groups are produced and reproduced (Narayan, 1998). The linguistic constructs of 'absolute' language that are used to describe groups of forcibly displaced women having the same experience despite their varying characteristics and identities works within the 'discourses of difference'. This displays the importance of conducting a critical discourse analysis in order to examine the 'discourses of difference' and how they are framed, which is evident in the use of language with absolute underlying meanings.

The gender and culture of forcibly displaced women can be essentialized through these 'absolute' terms because they paint the picture of experiences through homogenous constructions of gender and culture. As stated in the conceptual framework, a gender binary is a dominant 
construction of gender as being a dichotomy of masculinity and femininity. Culture is fluid and have variations within them, rather than being distinct and sharply defined (Narayan, 2000). In the discourse of the Handbook, the prevalence of terms with 'absolute' meanings rather than terms with 'relative' connotations creates essentialist representations the experiences of forcibly displaced women based on the lines drawn by their gender and cultures, primarily from the Global South. Cultural essentialism is embodied in the representations of refugee women as being reduced to characteristics of their culture, rather than their own characteristics as individuals. The historical and political processes that have contributed to creating characteristics which are deemed 'central components' of the culture are not taken into account when representations of cultural essentialism occur (Narayan, 2000). The way that culture is spoken about by the Global North for the Global South, or the 'other', is in a way that is homogenizing based on particular characteristics of race, class, and rights.

\subsection{4 'No one' and 'Some'}

The use of the terms 'no one' and 'some' are also constructed as absolute and relative terms based on their underlying meanings in relation to they statements they are included in:

"No one is spared the violence, but women and girls are particularly affected because of their status in society and their sex" (UNHCR. 2008, p. 7).

For some women and girls, survival sex becomes the only way to support themselves and their families (UNHCR, 2008, p. 10).

In some cases, they may find themselves face to face with their rapists and attackers and be forced to live in fear and silence, as cultural taboos and the absence of support have kept the crimes hidden and protected the perpetrators (UNHCR, 2008, p. 11).

The term 'some' acquires a 'relative' meaning because it does not capture the entire group or even describe the majority. It does not contribute to essentialism because the use of this 
term signifies it being dependent on circumstances and being applicable to forcibly displaced women depending the intersections of their oppression. Forcibly displaced women are diverse in that they come from a variety of racial, ethnic, and class background, with a range of different ages, education levels, and political alignments (Moussa, 1998). The intersecting systems of oppression do not affect women in the same way, rather these experiences are dependent on race, ethnicity, class, sexuality, religion, age, or education (Edward, 2007). These produce complexities in the experiences of forcibly displaced women (Edward, 2007). The way that discourse is constructed in the acquired meanings to 'absolute' and 'relative' terms contributes to essentialist representations of forcibly displaced women. Recognizing that women have different experiences is necessary for understanding the heterogeneity of gendered persecution (Mohanty, 2003). Using language that has meanings of relativity and openness allows for the nuance of intersections of oppression that affect the experiences of forcibly displaced women.

The statements with terms that acquire 'absolute' meanings in this discourse do not allow for nuance within the discussion of the many experiences of forcibly displaced women. Terms with 'absolute' meanings create a specific representation of a broad group because the terms do not allow for variations in their description, which results in essentialism. There are significant implications for the essentialist representations of forcibly displaced women. Essentialist generalizations can cause theoretical perspectives and political agendas that remove the issues and concerns of many women that are marginalized through their class, race, ethnicity, and sexual orientation (Narayan, 1998). As a result, the concerns for forcibly displaced women are not adequately addressed and they continue to face marginalization. 


\subsection{Western Perspective}

The last coding category of this critical discourse analysis is the Western perspective which is implicit in the Handbook through the particular terms examined, the use of 'we', 'us', 'our', and 'ourselves'. These terms are referring to the UNHCR and those reading the Handbook for the purpose of contributing to the protection of women, which is clear by the stated purpose and audience of the Handbook.

\subsubsection{UNHCR Position}

The UNHCR acknowledges and explains its position in the Handbook in the interest of showing their transparency:

Protecting women and girls therefore demands that we look at our own values and attitudes towards the roles and identities of women and girls, and towards gender and power relations. Our own socially constructed identity affects how we respond to the individuals with whom we work, both in the office and in operations. It is important to recognize and understand that

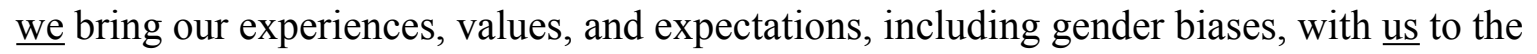
workplace. Greater self awareness is required to be sure that we adopt an open attitude towards others, including in particular people of concern, and are able to learn from them and build mutual trust (UNHCR, 2008, p. 18).

It is not enough to simply acknowledge the position of the UNHCR as not fully understanding the protection issues for forcibly displaced women, while still creating a discourse that has representations that are essentialist and victimizing. Though the Handbook is wellintentioned in its taking on a feminist perspective to address issues of gendered risk and protection for forcibly displaced women, it's application of feminist theory falls short as it is rooted in global feminism. Within global feminism, Western feminists are the 'subjects' and women of the Global South are the 'objects' (Mohanty, 1988). The global feminist discourse defines women of the Global South as being outside of social relations, rather than examining the ways that social structures constitute them as women (Mohanty, 1988). The Handbook 
acknowledges its position in relation to the women it is discussing, but it still contributes to the discourse there is a universal feminist approach that can be applied to all issues, thus erasing the possibility of women's own agency in finding solutions to their issues, rather than it contributing a more inclusionary stance.

\subsection{2 'We' and 'Us'}

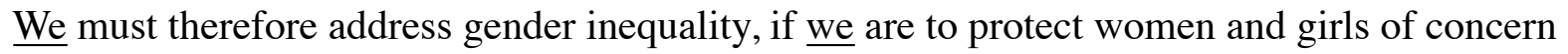
(UNHCR, 2008, p. 13).

Protecting women and girls thus requires us to adopt an extremely positive approach (UNHCR, 2008 p. 17).

Understanding the context and dynamics of communities of concern and working in partnership with them are critical if we are to enhance the protection of women and girls (UNHCR, 2008, p. 17).

In humanitarian situations, it is the Western countries and international bodies of the United Nations that are able to offer the most support to those who are in need. There is a power inequality between those in a position to protect and those in need of protection. The language of 'we', 'us', 'our', and 'ourselves' raises questions about who is included and who is excluded in the decision-making process of the UNHCR. This language also creates a distinct line drawn between the positions of the West and the 'other'. It draws this line through the differences in power and participation. The 'we' does not include forcibly displaced women because their voice is not reflected in the Handbook.

Western feminism constructs an image of the 'Third World Woman' through hierarchies of colonization (Mohanty, 1988) and this process is also evident in the discourse of the way protection and gendered risk for forcibly displaced women are discussed by the UNHCR. According to Mohanty (1988), the 'singular monolithic subject' image of 'Third World women' 
is constructed through particular analytical categories. Razack (1998) states that "when Western feminists speak about prostitution, pornography, mass rapes, domestic violence, dowry burnings, and genital mutilation, they have often done so using the universal 'we.' In doing so, differences between women of the Global North and Global South have almost entirely disappeared. The multiple sources of sexualized violence remain uninterrogated as do the many ways in which women are complicitous in oppressing other women.” (p. 94). The dichotomy constructed between 'Western women' and 'Third World women' is problematic because there are not only sharp contrasts created between the 'Western woman' and the 'Third World woman', but this also creates a hierarchy among cultures by making the distinction between the victim and the agent. Relying on the essentialized Western view refugee women's experiences from the 'Third World' is not only inapplicable, but it is also racist (Razack, 1996b). It also excludes the possibility of including 'these' women in their own solutions. Thus, it is evident that the discourse of 'Othering' contributes to this image, through the divisive positions of 'us' vs. 'them' .

There is a category of analysis used in the Western feminist discourse of women of the Global South, which constructs them as a homogenous, powerless, and victims of their cultural and socio-economic systems (Mohanty, 1988). This power relation plays a role in the process of essentialism due to the unequal relations that feed into the discourse of victimization, where forcibly displaced women are being saved because they cannot save themselves. The nuance in the variation of experiences for refugees and internally displaced women is an important part of the discourse and representation, because it relates to the treatment and protection of forcibly displaced women in society. The intention in the Handbook is clear, but the reality is that these pronouns contribute to the construction of a Self vs. Other relationship in terms of the divide of 
power and oppression. One side of this dichotomy is in a position to take action, whereas the other side receives the assistance.

\subsection{Conclusion of the Critical Discourse Analysis}

It is important to examine discourse in terms of the underlying meanings and linguistic constructs that words and terms acquire based on the way in which they are used. The intentions of the discourse are not the focus in this analysis, but rather the implications of the way the feminization of forced displacement is framed in terms of the constructed representations of forcibly displaced women. This critical discourse analysis of the UNHCR Handbook for the Protection of Women and Girls demonstrates that representations of forcibly displaced women are constructed within a gender binary, embedded in the discourse of victimization, gender and cultural essentialism, and through a Western perspective rooted in global feminism. 


\section{Discursive Implementation of Policy: A Case Study of Canada's Role}

The UNHCR has influential international documents on the protection of forcibly displaced women, through its detailed guidelines on gendered persecution and the involvement of women in the UNHCR's delivery of programs (Hajdukowski-Ahmed et al., 2013). That being said, there is a gap that exists between policies and their implementation (Hajdukowski-Ahmed et al., 2013), which has direct implications for forcibly displaced women because their protection is theoretical rather that practical. Implementation in this sense is not being questioned in terms of its intention or resources. It is rather the conceptual and discursive framing of policies, being that the discourse is not in the best interest of forcibly displaced women. Whether these policy changes have been taken from theory and put into practice in the field is largely dependent on the social acceptance of the discourse. The particular language chosen as part of the discursive practices can create ambiguities or representations of forcibly displaced women, which creates barriers for the proper acceptance and adherence of states to the policies, guidelines, and handbook.

The experiences of refugee women "have not always been properly captured or reflected in legal and policy instruments and servicing them" (McPherson, 2014, p. 3).The fact that the United Nations guidelines are not legally binding further complicates the way that support can be secured for forcibly displaced women, in addition to the issue that policies are not being adequately implemented by states (Obradovic, 2015). Though the intended audience for the Handbook is UNHCR staff, its discourse has wider implications because it is an international document used for other purposes, such as influencing state policies as a result of the socially constructed representations of forcibly displaced women. 
The discourse that frames the representations of forcibly displaced women through UNHCR documents plays a role in the way states accept and shape their policies regarding forcibly displaced women. In order to strengthen the Handbook, its principles should be applied evenly to all policies, refugee determination cases, and settlement services by the Canadian government and non-governmental organizations. It is important to examine Canada's role in the support and enhancing the rights of refugee women in terms of the government's involvement in national policy implementation and international policy advancement. As previously explained, implementation is being discussed in terms of its conceptual framework within policies. This short case study will be used to draw linkages between the Handbook's discourse about the representations of forcibly displaced women and the recognition for supporting refugee women in the Canadian legal system.

Canada has played an instrumental role in the advancements for protecting refugee women (Hajdukowski-Ahmed et al., 2013). Canada was the first country to participate in the UNHCR Women at Risk Programme in 1988, which advocacy groups anticipated would create a gender balance in the number of refugees that Canada would admit (Moussa, 1998). In 1993, Canada became the first country to adopt formal guidelines for the adjudication of refugee claims for gendered persecution (Edward, 2007). The accomplishments of the Canadian government also include being the first country to establish a resettlement plan for at-risk refugee women and being active in the UN Security Council's adoption of the Resolution 1325 on Women, Peace, and Security (Hajdukowski-Ahmed et al., 2013). Hajdukowski-Ahmed et al., (2013) support the strength of Canada's involvement by stating, "Canada has been relentless in reminding the 
UNHCR, at all levels, of the agency's fundamental obligation to protect and assist refugee women" (p. 220).

Though Canada has been a leader in policy development for the support of refugee women, there are gaps in fully recognizing gendered risks and the representation of the experiences of refugee women. Moussa (1998) states that feminists criticize the United Nations and Canadian policies in the lack of inclusion of gender oppression in their definition of a refugee, which results in women not receiving the necessary protection. To apply refugee law in a uniform way towards men and women serves to exacerbate their pre-existing inequalities in society (Moussa, 1998). Global feminists do not advocate for non-gendered refugee law, as this does not adequately address the inherent power relations, but the construction of a gender binary in Canadian refugee law is also part of a problematic discourse.

Refugee women are represented as victims or recipients of humanitarian aid in Canadian refugee policy (Razack, 1998). This discourse has implications for identities as victims rather than survivors, which could become internalized through the way they are treated by service providers. It is essential to ensure that those in control of the refugee determination system receive adequate education on tools to analyze gender-based refugee claims, as they have the power to directly affect the fate of refugee women gaining legal protection in Canada (Moussa, 1998). The critical discourse analysis in this paper displays that the expectations for the stories of gender-based refugee claims should not be informed by the discourse of victimization or essentialist representations of forcibly displaced women. It is also necessary that there be an ongoing assessment of the implementation of Canadian policies to support refugee women, in order to determine their effectiveness and acceptance (Moussa, 1998). This directly relates to the 
critical discourse analysis conducted in this paper on the framing of the feminization of forced displacement, as the implementation of these policies is being examined through the way the discourse is accepted and legitimized. The actions within the Canadian refugee determination system should not embed the discourse that currently frames forcibly displaced women, but it will continue to hinder their representations.

The Canadian Council of Refugees (2013) critiques the refugee and immigration issues for women and girls, based on policy changes that arose in 2012 to the refugee determination system. The critique is based on the fact that the reformed Canadian refugee determination system does not take a properly gendered analysis nor does it address how the changes affect women and girls (Canadian Council for Refugees, 2013). These gaps may be based on misrepresentation of refugee women and their lack of involvement or voice in the system, which also may be due to their representations as bodies without autonomy or agency. Through this case study, it is evident that state involvement in policies and international documents does not necessarily result in proper fulfillment of implementation for those who the policies supposedly support, as a result of representational issues in the discourse about at-risk groups. 


\section{Conclusion}

This Major Research Paper sought out to answer the questions: How are UNHCR documents gendered to protect forcibly displaced women? How does the UNHCR Handbookfor the Protection of Women and Girls frame the gender-based risks and needs of forcibly displaced women? How does the UNHCR Handbook for the Protection of Women and Girls contribute to the discourse on the representations of forcibly displaced women? The critical discourse analysis has examined the ways the language and terms acquire underlying meanings which construct knowledge and 'truth', in addition to re-inscribing hierarchical power relations through discourse, despite good intentions. It has been found that the discourse of the UNHCR Handbook for the Protection of Women and Girls constructs representations of forcibly displaced women that are based on a gender binary, gender and cultural essentialism, victimhood, and Orientalism through the Western perspective. All of these components of the conceptual framework have been applied in order to demonstrate the problematic discourse that constructs misrepresentations for forcibly displaced women.

As a result of length and time constraints of this Major Research Paper, the entire document of the UNHCR Handbook for the Protection of Women and Girls has not been examined and further research on a larger scale of data analysis is necessary in order to draw conclusions based on the entire document. Going forward, those in position of power to contribute to both international documents and national policy pertaining to forcibly displaced women, must intentionally engage in discursive practices that do not continue to construct these misrepresentations of forcibly displaced women as part of the gender binary, as essentialized 
groups, as victims, or as the 'Other'. There is a need for a much more complex multidimensional understanding of forcibly displaced women rather than 'victim' or 'survivor'. 


\section{References}

Baker, P., Gabrielatos, C., Khosravinik, M., Krzyżanowski, M., McEnery, T., \& Wodak, R. (2008). A useful methodological synergy? Combining critical discourse analysis and corpus linguistics to examine discourses of refugees and asylum seekers in the UK press. Discourse \& Society, 19(3), 273-306.

Betts, A., Loescher, G., \& Milner, J. (2008). UNHCR: The politics and practice of refugee protection into the 21 st century. Routledge.

Boyd, M. (1999). Gender, refugee status and permanent settlement. Gender Issues, 17(1), 5-25.

Buscher, D. (2009). Women, work, and war. In Women, Migration, and Conflict (pp. 87-106). Springer Netherlands.

Buscher, D. (2010). Refugee women: Twenty years on. Refugee Survey Quarterly, 29(2), 4-20. Canadian Council for Refugees. (2013). Key Immigration and Refugee Issues for Women and Girls. Retrieved August 282016 from: http://ccrweb.ca/sites/ccrweb.ca/files/womens-issues-march2013.pdf.

Castles, S., \& Miller, M. J. (2009). The age of migration: International population movements in the modern world (4th ed.) Palgrave Macmillan.

Cohn, C. (Ed.). (2013). Women and wars: Contested histories, uncertain futures. John Wiley \& Sons.

Creswell, J. W. (2013). Research design: Qualitative, quantitative, and mixed methods approaches. Sage publications.

Edward, J. K. (2007). Conceptual Framework. In Sudanese Women Refugees (pp. 49-61). Palgrave Macmillan US. 
Gerard, A. (2014). The securitization of migration and refugee women. Routledge.

Ghosh. S. (2016). Lecture on Nature and Volume of International Migration to Canada. Ryerson University, Toronto, Ontario.

Giles, W. (2013). Women Forced to Flee: Refugees and Internally Displaced Persons. Women and wars: Contested histories, uncertain futures. John Wiley \& Sons.

Gill, R. (2000). Discourse analysis (pp. 172-190). Sage Publications.

Grabska, K. (2011). Constructing 'modern gendered civilised' women and men: gendermainstreaming in refugee camps. Gender \& Development, 19(1), 81-93.

Grillo, T. (1995). Anti-essentialism and intersectionality: Tools to dismantle the master's house. Berkeley Women's LJ, 10, 16.

Gusman, J. L. (2013). Recognizing the feminization of displacement: a proposal for a genderfocused approach to local integration in Ecuador. Pac. Rim L. \& Pol'y J., 22, 429.

Hajdukowski-Ahmed, M., Khanlou, N., \& Moussa, H., (Eds.). (2013). Not born a refugee woman:Contesting identities, rethinking practices (Vol. 24). Berghahn Books.

Hall, S. (Ed.). (2007). The West and the Rest: Discourse and Power from Race and Racialization: Essential Readings (pp. 56-60). Canadian Scholars' Press Inc. (Original work published in 1996)

Hart, C. (2008). Critical discourse analysis and metaphor: Toward a theoretical framework. Critical discourse studies, 5(2), 91-106.

Hyndman, J., \& Giles, W. (2011). Waiting for what? The feminization of asylum in protracted situations. Gender, Place \& Culture, 18(3), 361-379. 
Indra, D. (1993). Some feminist contributions to refugee studies. Gender Issues and Refugees: Development Implications, 757-66.

Johnson, H. L. (2011). Click to Donate: visual images, constructing victims and imagining the female refugee. Third World Quarterly, 32(6), 1015-1037.

Kapur, R. (2002). Tragedy of Victimization Rhetoric: Ressurecting the" Native" Subject in International/Post-Colonial Feminist Legal Politics, The. Harv. Hum. Rts. J., 15, 1.

LaViolette, N. (2007). Gender-related refugee claims: Expanding the scope of the Canadian guidelines. International Journal of Refugee Law, 19(2), 169-214.

Lee, C. (1989). The Forgotten Majority. Canadian Woman Studies, 10(1).

Macklin, A. (2009). Legal aspects of conflict-induced migration by women (pp. 23-45). Springer Netherlands.

Mahler, S. J., \& Pessar, P. R. (2006). Gender matters: Ethnographers bring gender from the periphery toward the core of migration studies. International migration review, 40(1) $27-63$.

Malkki, L. H. (1996). Speechless emissaries: Refugees, humanitarianism, and dehistoricization. Cultural anthropology, 11(3), 377-404.

Martin, S. F., \& Tirman, J. (Eds.). (2009). Women, Migration, and Conflict. Springer Netherlands.

McPherson, M. (2014). Refugee women, representation and education: creating a discourse of self-authorship and potential. Routledge.

Mohanty, C. T. (1988). Under Western eyes: Feminist scholarship and colonial discourses. Feminist review, (30), 61-88. 
Mohanty, C. T. (2003). Feminism Without Borders (Durham, NC. Duke University Press, 224, $16-18$.

Moussa, H. (1998). Violence against refugee women: Gender oppression, Canadian policy and the international struggle for human rights. Resources for Feminist Research, 26(3/4), 79.

Narayan, U. (1998). Essence of culture and a sense of history: A feminist critique of cultural essentialism. Hypatia, 13(2), 86-106.

Narayan, U. (2000). Undoing the" package picture" of cultures. Signs, 25(4), 1083-1086.

Obradovic, M. (2015). Protecting Female Refugees against Sexual and Gender-based Violence in Camps. Humanitarian Affairs: Human Security, Migration, Vulnerabilities, Women.

Parpart, J. L., Rai, S. M., \& Staudt, K. A. (Eds.). (2003). Rethinking empowerment: Gender and development in a global/local world. Routledge.

Piper, N. (2006). Gendering the Politics of Migration1. International Migration Review, 40(1), 133-164.

Rathgeber, E. (1990). WID, WAD, GAD: Trends in Research and Practice. The Journal of Developing Areas, 24(4), 489-502. Retrieved from http://www.jstor.org/stable/4191904

Razack, S. (1996a). Beyond universal women: Reflections on theorizing differences among women. UNBLJ, 45, 209.

Razack, S. (1996b). The perils of storytelling for refugee women. Development and diaspora: Gender and the refugee experience, 164-175.

Razack, S. (1998). Looking white people in the eye: Gender, race, and culture in courtrooms and classrooms. University of Toronto Press. 
Rider, E. (2012). Refugees, Sexual Violence, and Armed Conflict: The Nuances between Victims and Agents1. Wagadu: a Journal of Transnational Women's and Gender Studies, 10, 72.

Said, E. W. (1979). Orientalism. Vintage.

UNHCR. (2008) Handbook for the Protection of Women and Girls, Geneva, Switzerland:

\section{UNHCR.}

UNHCR. (2016). Figures at a Glance. Retrieved August 13, 2016, from http://www.unhcr.org/ figures-at-a-glance.html

Vause, S., \& Toma, S. (2015). Is the Feminization of International Migration Really on the Rise? The Case of Flows from the Democratic Republic of Congo and Senegal. Population, English edition, 70(1), 39-62.

Veney, C. R. (2007). Forced migration in Eastern Africa: democratization, structural adjustment, and refugees. Palgrave Macmillan.

Verschuur, C. (2013). Theoretical debates on social reproduction and care: The articulation between the domestic and the global economy. Oso Casas L., Ribas Mateos N., International Handbooks on Gender Series, 145-161.

World Bank. (2015). The Global Program on Forced Displacement (GPFD). Retrieved June 11, 2016 from http://www.worldbank.org/en/programs/forceddisplacement.

Zetter, R. (1999). International perspectives on refugee assistance. Refugees: Perspectives on the experience of forced migration, 46-82. 